
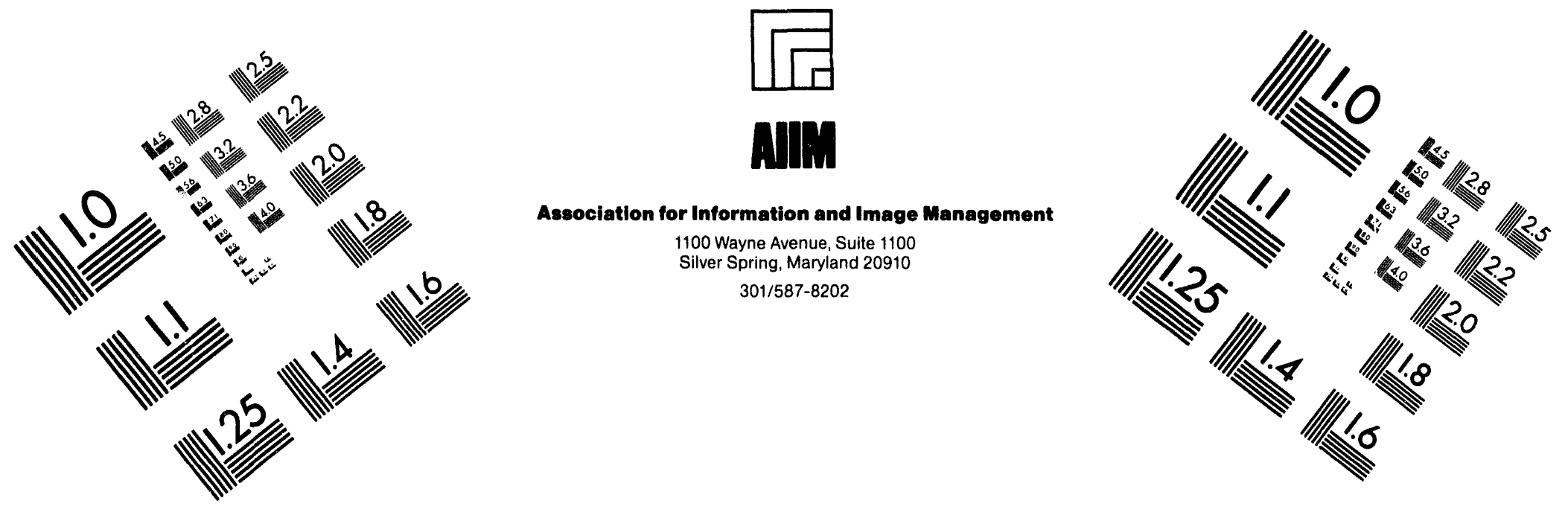

Centimeter

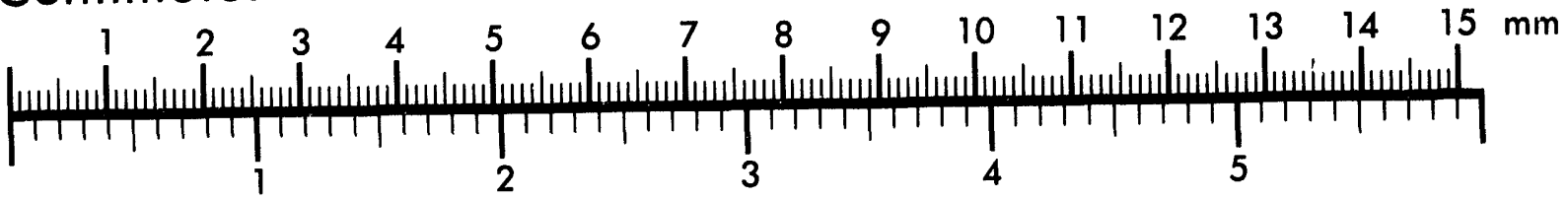
Inches
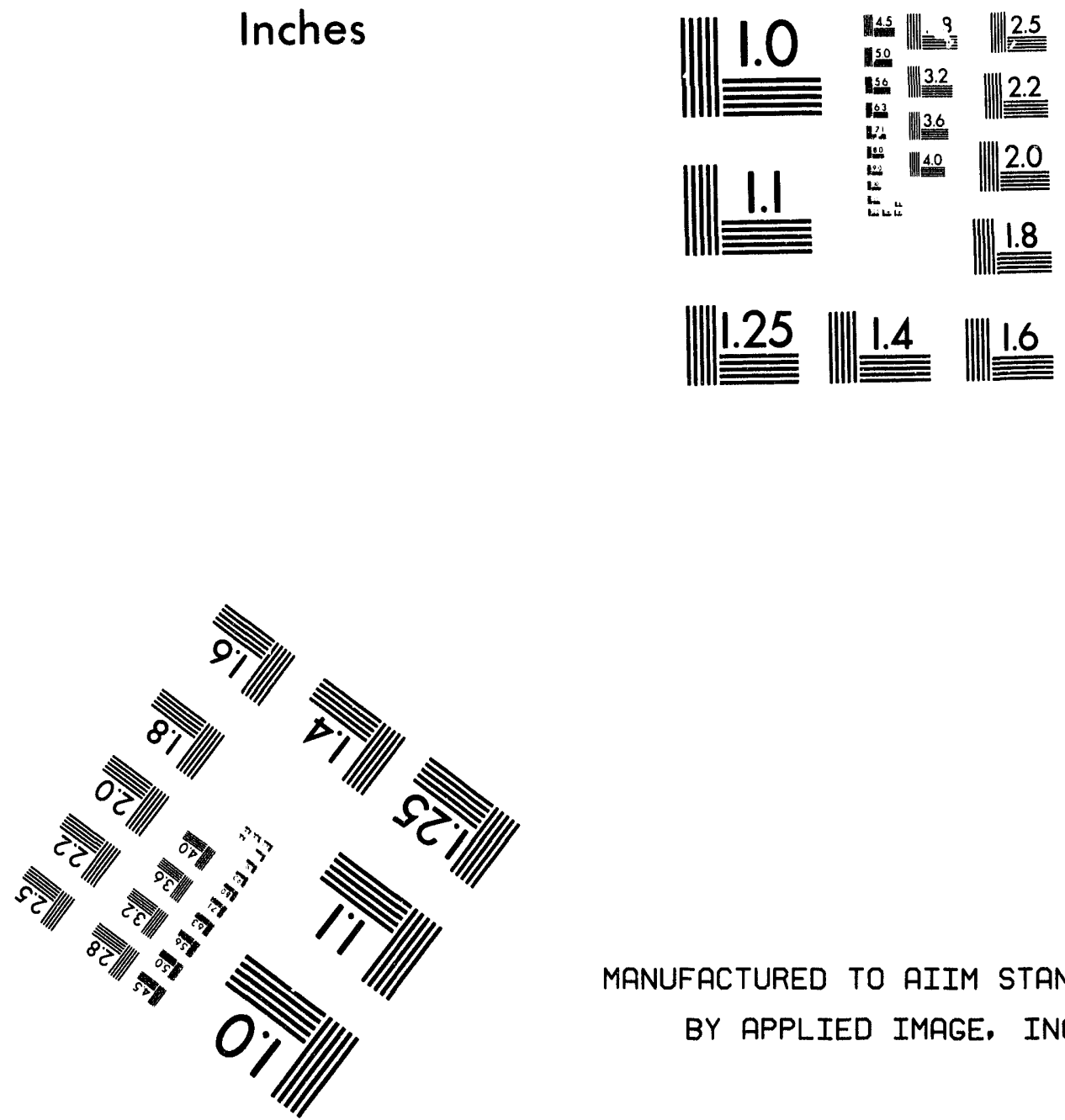

MANUFACTURED TO AIIM STANDARDS

BY APPLIED IMAGE, INC.

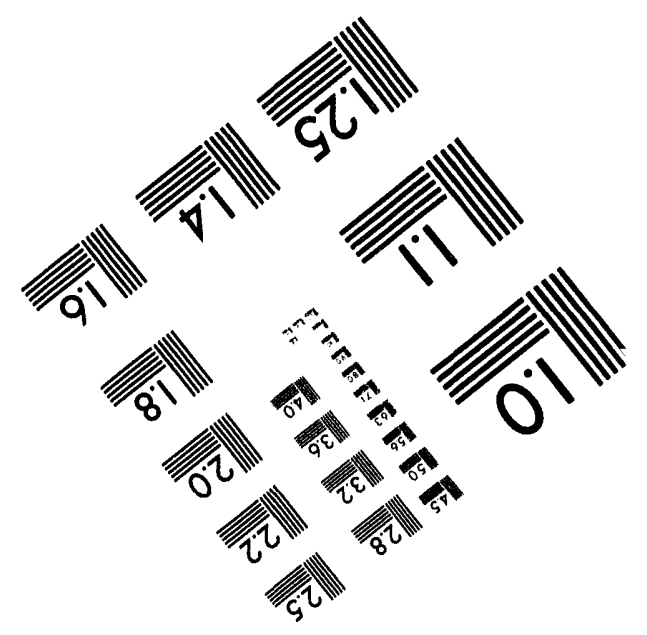



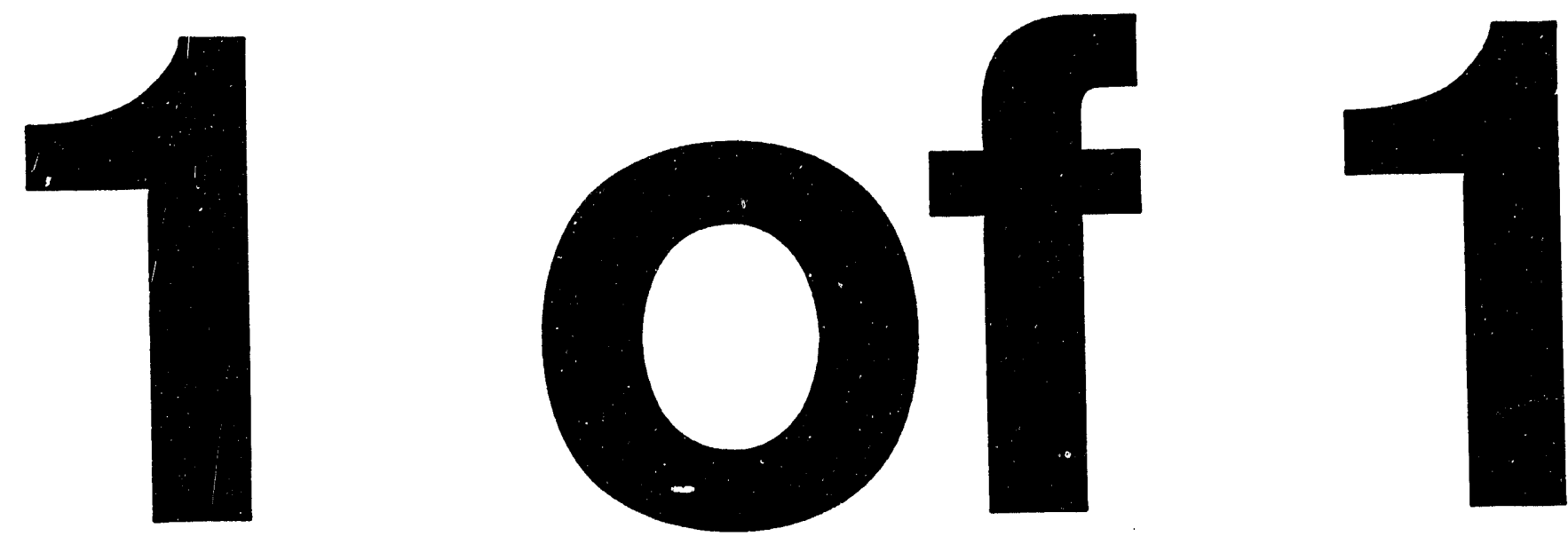
LA-UR- 941791

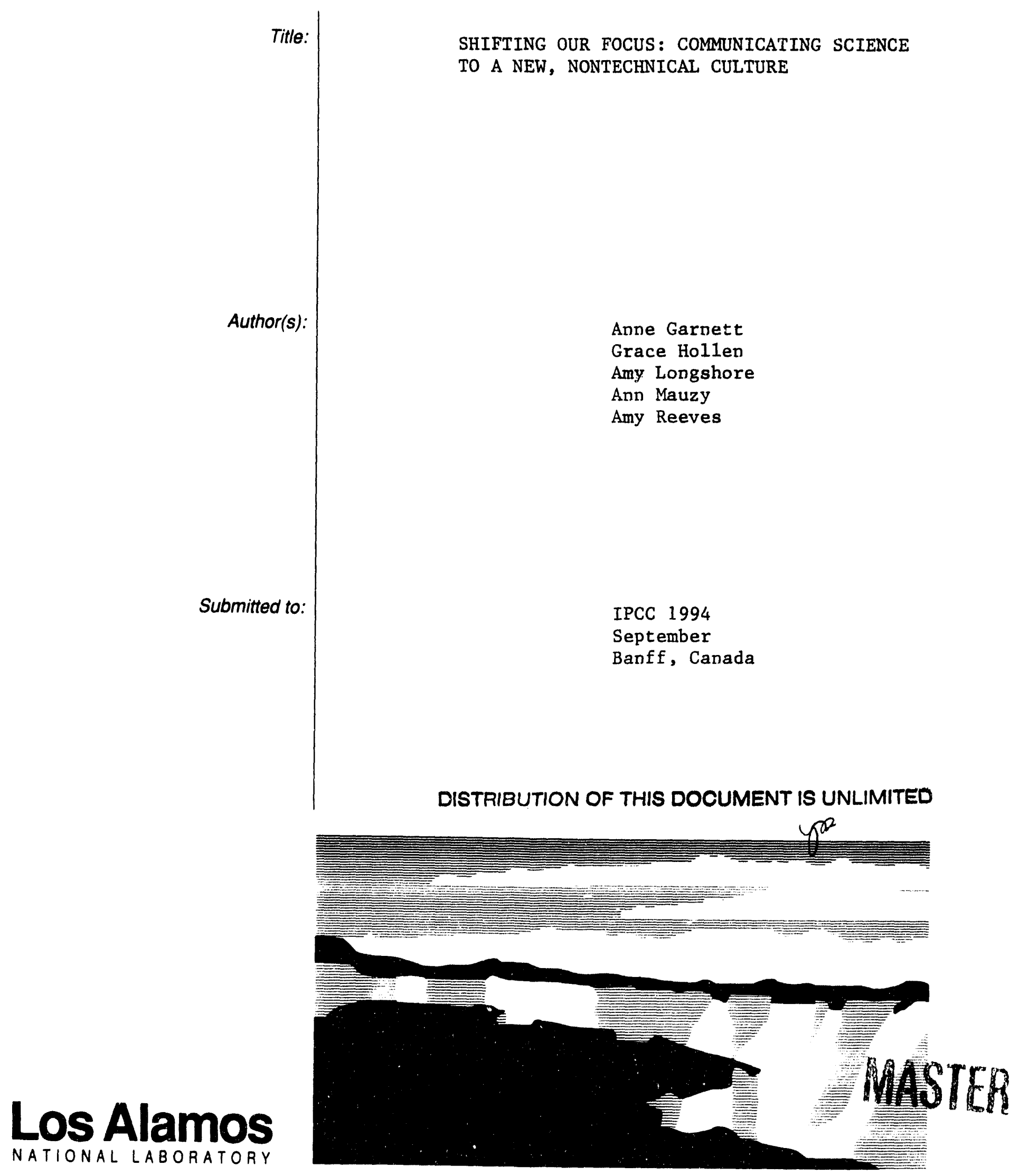

Los Alamos National Laboratory, an affirmative action/equal opportunity empidyer, is operated by the University of California for the U.S. Department of Energy under contract W-7405-ENG-36. By acceptance of this article, the publisher recognizes that the U.S. Government retains a nonexclusive, royalty-free license to publish or reproduce the published torm of this contribution. or to allow others to do so, for U.S. Government purposes. The Los Alamos National Laboratory requests that the publisher identify this anticle as work pertormed under the auspices of the U.S. Depantrent of Energy. 


\title{
Shifting our Focus: \\ Communicating Science to a New, Nontechnical Culture
}

Ann Mauzy
for the panel
(505)667-5387
email: mauzy@lanl.gov

Los Alamos National Laboratory

Post Office Box 1663

Mail Stop D416

Los Alamos, NM 87545

\begin{abstract}
Congress' decision to close down the $\$ 11$ billion Superconducting Supercollider is spreading anxiety throughout the scientific community. As funding for the nation's research laboratories becomes increasingly scarce, technical communicators in these organizations must focus much of their communications efforts on a new culture: Congress and the public. We discuss how to characterize this new audience and the importance of evaluating communication products, and we highlight some strategies for interpreting science to nonscientists more effectively.
\end{abstract}

\section{General Audiences versus Technical Audiences}

With a changing political and economic climate in the United States, Los Alamos National Laboratory (LANL), a Department of Energy research laboratory, must more actively compete for funding and as a result needs to communicate scientific information effectively to a more diverse audience. In the past professional communicators at LANL primarily concentrated on communicating scientific and technical information to expert members of the scientific community. Recently, however, a group of these communicators began developing expertise in communicating scientific and technical information to a nontechnical community, the "invisible" public.

The increased demand at LANL to relay science to this invisible audience has prompted us to undertake a study, which we began by searching existing literature for strategies in targeting the public, effectively communicating messages to the 
public, and evaluating whether the public will receive and understand the messages.

\section{The Need for Communicating Science to the Public}

The public is clearly interested in science and technology. This interest is illustrated by the sale of more than one million hard-cover copies of Steven Hawking's A Brief History of Time (Bantam, New York, 1988). Millions watch "Nova," and millions more devour books, movies, and television shows such as "Star Trek" and its progeny. In spite of such interest, however, only 7 percent of all American adults are scientifically literate according to Hazen and Trefil in their book Science Matters (Doubleday, New York, 1991). Their definition of science literacy is "enough general knowledge to understand the daily news as it relates to science and the ability to put it into context the same as one would with news in any other area." They point out that if the public is not informed and involved in decisions that relate to science and technology debate, such decisions will be made by demagogues, at worst, or by a scientifically literate but unelected elite, at best. The issues include energy choices, genetic engineering of food, the greenhouse effect, cures for diseases, disposal of toxic and nuclear wastes, and protection of air and water quality. As science communicators, we share the duty of scientists to help citizens understand such issues.

Reporting in Nature ("The growing inaccessibility of science," Vol. 356, 1992), Cornell sociologist Donald P. Hayes says that until about 1960 the public could get its information on science and technology from such publications as Nature, Science, and Physics Today. Evaluating these with his ndex of "lexical difficulty," which is based on the way 10,000 common words are used in English-language newspapers, he concludes that today such publications are so technical as to be inaccessible to nearly everyone but experts in the narrow fields addressed in specific articles. He cautions that erecting barriers to the comprehension of science will diminish science itself and threaten "its openness to cutside examination and appraisal."

\section{Targeting Audiences}


The stakes, then, are high. Communicators need to target the public as the most important audience and to urge scientists to do the same. But we must first learn the characteristics of this huge audience and their preconceptions about science in order to produce effective communications.

The public includes everyone-high school dropouts, lawyers, travel agents, waiters, and physicists. Surveys performed by John Durant and Glynis Breakwell showed that the public perceives themselves as being very or moderately interested in news about discoveries or inventions but. poorly informed about science issues compared with sports, politics, or films. (J. Ziman, "Not Knowing, Needing to Know, and Wanting to Know," in B. V. Lewenstein, Ed., When Science Meets the Public, [American Association for the Advancement of Science, 1992], pp. 13-20).

Jon Miller, head of the International Center for the Advancement of Scientific Literacy, classifies the public as attentive or nonattentive with respect to science policy ("Scientific Literacy in the United States," in Communicating Science to the Public, [John Wiley \& Sons, 1987], pp. 19-40). He points out that the nonattentive public should not be considered ignorant. Many are well educated, interested in policy issues other than science, and politically active. Marcell LaFollette categorizes the public as friends of science (including scientists themselves), buyers-managers of science (R\&D administrators, government officials, and members of Congress), viewers (the general audience), and benevolent critics. ("Beginning with the Audience," in When Science Meets the Public, pp. 33-39).

Our audiences carry with them preconceptions and misconceptions that color their perception of our message. Minda Borun reminds us that "we are not dealing with a 'clean slate,' onto which we may indelibly inscribe explanations. People interpret what they see and experience in terms of their own notions. In informal encounters with phenomena, they arrive at a number of partially correct explanations" ("Naive Notions and Science Learning," in Visitor Studies-1988: Theory, Research and Practice, S. Bitgood, J. T. Roper, Jr., and A. Benefield, Eds., [Center for Social Design, 1988], pp. 135-138). However, this dynamic relationship between audience predispositions and our message frequently goes unnoticed in the planning process.

\section{Evaluation}


Although we tend to think of evaluation as something to do after we have a finished communication product, evaluation should begin before the product is written, photographed, illustrated, videotaped, or designed. The first step in frontend evaluation is to ask if the product is needed. Answers to this question provide a statement of the problem to be addressed, the intended audience, a decision as to the most appropriate medium, the cost benefits (if any) for producing the product, and the worth of the product to the organizacion as a whole and to other stakeholders.

A product can have great production values but still not be functional. The second step in front-end evaluation, then, is to ask if the product will be functional, that is, will it bring about a desired change, greater knowledge, or more appropriate attitudes? All members of the production team should be involved in this step. Answers to these questions provide statements of the goals for the final product. Goals may be "feeling" statements, such as "audience will appreciate. .." or "audience will feel good about. ..." Goals may not be measurable, but from these goals come the objectives that will be measured as a part of the evaluation of the final product. Indeed, objectives must be observable, demonstrable, measurable, and specific. They are written in concise statements: "after reading this brochure, audience members will be able to list 3 facts. . .will be able to circle true statements. . .will be able to explain. .." Included in the objectives are the standards of performance that will be measured in the final evaluation steps. The final evaluation criteria, then, are written in the second step of the front-end evaluation.

Front-end evaluation provides important feed-in to design, production, and writing. It challenges the production team members to make sure that stated objectives are met. Because evaluation is most useful when it is done on a continuum, the third step in front-end evaluation is for the team to come up with an evaluation strategy: at what points will the product be evaluated, by whom, according to what criteria, and using what technique(s)? At this stage, the potential audience members should be involved. This is when the producers of a communication product find out what the audience members already know and how they feel about the subject. One revelation that comes out in this step is whether or not the message is actually what the client thinks it is. (A client may think people need to know the physics of how 
radiation is produced, but people may want to know only how to recognize radiation and how to avoid it.) Goals and objectives may need to be rewritten at this point.

Evaluation at any point may include interviews, focus groups, pencil-and-paper tests, and other techniques. Much has been written about each technique, when to use it, how to use it, how many participants to include, how to design questionnaires, how to score them, and how to statistically treat them, and many models have been offered by respective writers. It is not our intent to address this level of detail in this paper. However, one excellent source for these details is Evaluating Video Programs: Is It Worth It? by Laurel Sneed (Knowledge Industry Publications, Inc., New York 1991). Everything it says about video is equally applicable to other media. The book includes references at the end of each chapter, and it includes an appendix on software that can be used for evaluation and journal references on discussions of such software.

\section{Communication Strategies}

As science communicators, we become the gatekeepers of information and are therefore responsible for translating scientific messages to a variety of audiences, from various levels in the government to private industry and especially to the general public. We must be advocates for our audiences. Often, important funding and policy decisions are based on the readers' understanding of the benefits of basic research and new technology. Through interview's, personal contacts, and self-directed research, we must translate scientific ideas that "often involve difficult, esoteric language; difficult-to-picture structures or processes, or even difficult-to-believe notions, such as that the Earth is weightless" (K. Rowan, "What Research Says About Explaining Difficult Ideas," ASTC Newsletter, November/December 1992).

A number of useful writing techniques can help the communicator with the awesome task of translating scientific information to a nonscientific audience.

Keeping a file folder of useful information on various scientific topics can help the communicator with angles. points of view. and schemes for scientific articles. Most communicators use techniques garnered from instructional material or their own experiences. Often, developing a student/teacher relationship with the scientist as 
teacher helps the technical communicator explain the results and benefits of basic and applied research and the physical processes involved. Moreover, the communicator can provide insight into difficult scientific ideas by experiencing the subject firsthand and then reporting on the experience. Reading material by scientists like James Trefil, Robert Hazzn, Isaac Asimov, or Victor Weisskopf, who have taken on the difficult task of explaining science to a general audience, can often help communicators better understand difficult concepts. Reading background information about a subject often gives the communicator the basics needed to ask the right questions during interviews.

Effective science communication often requires links to connect what a reader already knows with the new information that is to be learned-in essence, to make the new information relevant to the reader. The communicator should try to relate the new ideas to common experiences, if possible, using accessible analogies and examples. If possible, the communicator should try to address readers' possible misconceptions about the material being presented, replacing false notions with correct information.

If appropriate analogies are not available, the communicator should try to establish a conceptual framework in which readers can assemble the new information. These advance organizers can take many different forms: a clarifying short expository introduction, a title, a diagram, or even a single sentence that precedes the rest of the text. Such advance organizers are not simply summaries of the material presented later; instead, advance organizers present the information in a more abstract and general form, providing a sense of how the information is structured and how the ideas relate to one another so that readers can more easily integrate the new material with their existing knowledge (D.P. Ausubel, The Psychology of Meaningful Learning [Grune and Stratton, New York, 1963]).

Another useful technique involves placing structural clues within sentences. The successful use of this "given and new" technique, as explained by Judith Swan and George Gopen ("The Science of Scientific Writing," American Scientist 78, 550 [1990]), depends on the correct placement of material in either the topic position or the stress position within the sentence.

The topic position is located at the beginning of the sentence. Information in this position provides the reader with perspective and context. Material occupying this 
position provides the reader with linkage (looking backward) and context (looking forward). The information in the topic position prepares the reader for upcoming material by connecting it backward to the previous discussion. This "old information" in the topic position helps readers construct the logical flow of the argument, focusing attention on one particular strand of the discussion. If the topic position is constantly occupied by material that fails to establish linkage and context, readers will have difficulty perceiving both the connection to the previous sentence and the projected role of the new sentence in the development of the paragraph as a whole.

Readers naturally emphasize material that arrives at the end of a sentence, the stress position. Here the reader needs closure and fulfillment for complete understanding of the material. According to Gopen and Swan, if emphatic material arrives any other place in the sentence, the reader may emphasize material that the writer did not intend to stress. Thus, the writer might lose an important opportunity to influence the reader's interpretative process.

In addition to linking, analogies, the "given-new" technique, and structural clues, communicators can use mechanical devices such as action verbs, a mix of short and long sentences, or even sentences starting with "And" or "But" to enhance the information in the article. Short sentences or some simple fragments often lend an air of anticipation and excitement to the topic-this technique, if successful, can develop expectation. In addition, anecdotes can illuminate a subject or develop or clarify a difficult concept.

Finally, we offer a suggestion from Natalie Angier, a Pulitzer Prize-winning science reporter on the New York Times (Angier, Natalie, "Some Organized Notes on Science Reporting for a Mixed Audience," ScienceWriters, Spring 1992). She challenges us to imagine the unseeable:

I write about molecular things...I try to picture them as though they were performers on a stage, dancing, spinning, sliding, grasping. If people feel they can picture what's going on inside a cell, they feel much more at home with science... Your obligation is to make the unseeable visible. Do not be afraid to use your imagination. 


\section{Bibliography}

Our annotated bibliography includes more than eighty items on the need for the special skills of communicating science to the public, the difference between this public audience and technical audiences, how to characterize audiences, evaluation of communication products, and writing techniques for communicating with the public.

(2500 words including the title and address)

\section{DISCLAIMER}

This report was prepared as an account of work sponsored by an agency of the United States Government. Neither the United States Government nor any agency thereof, nor any of their employees, makes any warranty, express or implied, or assumes any legal liability or responsibility for the accuracy, completeness, or usefulness of any information, apparatus, product, or process disclosed, or represents that its use would not infringe privately owned rights. Reference herein to any specific commercial product, process, or service by trade name, trademark, manufacturer, or otherwise does not necessarily constitute or imply its endorsement, recommendation, or favoring by the United States Government or any agency thereof. The views and opinions of authors expressed herein do not necessarily state or reflect those of the United States Government or any agency thereof. 

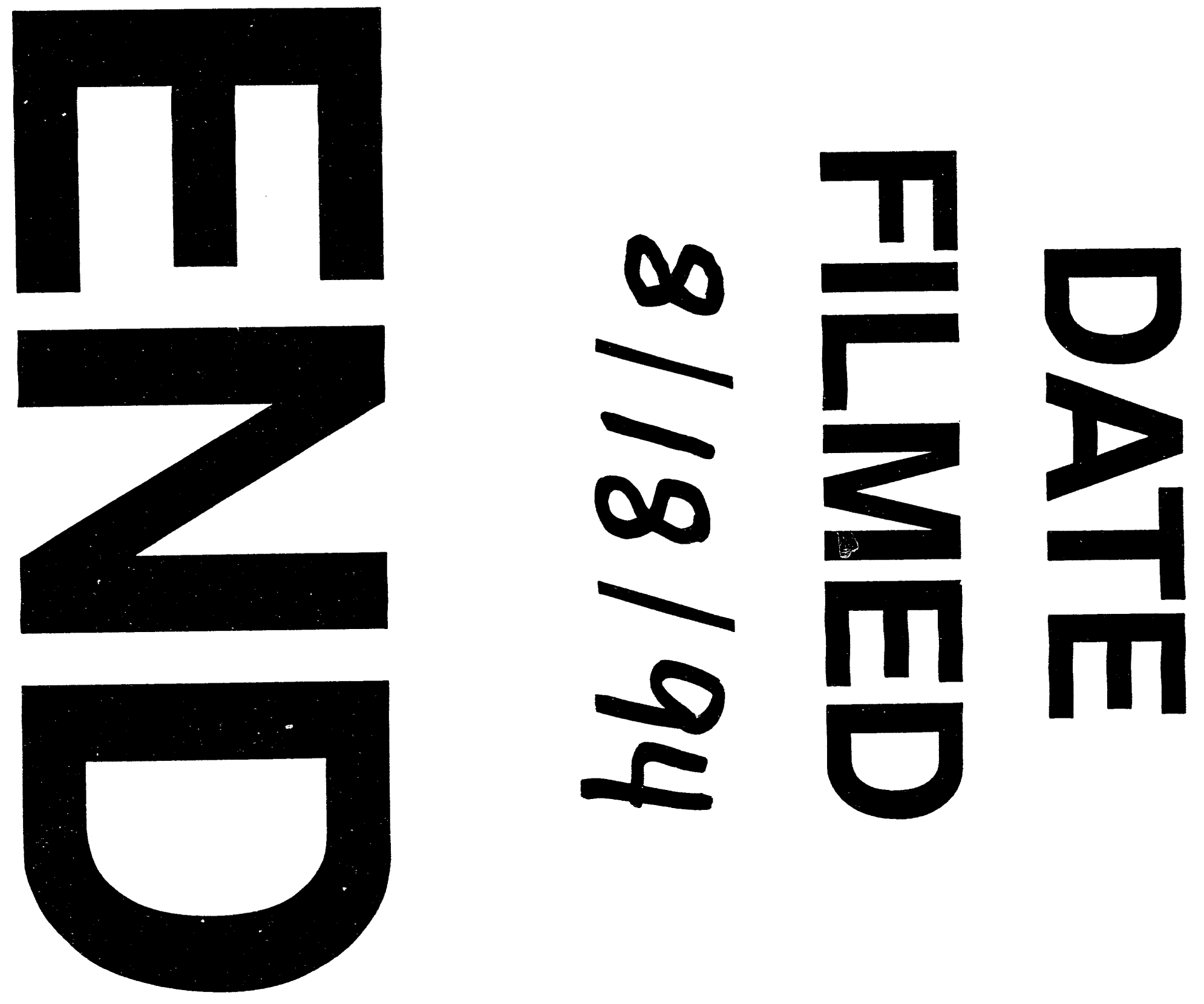
